\title{
Image Segmentation Techniques: An Overview
}

\author{
Maninderjit Kaur ${ }^{1}$, Er. Navdeep Singh ${ }^{2}$ \\ ${ }^{1,2}$ Department of Computer Engineering (UCoE), Punjabi university Patiala
}

\begin{abstract}
Image segmentation means extracting the part of an image or any object.In digital image processing, image segmentation plays a vital role in the processing of images. Image segmentation is one of the most important steps leading to the analysis of processed image data. The goal of image segmentation is pattern recognition and image analysis besides simplifying the representation of an image which is more meaningful. It is used in various applications like medical imaging, machine vision, traffic control systems, image recognition tasks etc.In this paper, review of various image segmentation techniques and comparison between different techniques is done.
\end{abstract}

Keywords: image Segmentation, quad tree, Ostu's method, clustering, k-mean clustering

\section{Introduction}

Image segmentation refers to the process of partitioning/subdividing an image into disjoint regions that are meaningful. The level to which subdivision is carried out depends upon the problem being solved. Segmentation should stop when the objects of interest is isolated. It can be used for object recognition, image compression, image editing etc. It represents the result with binary images; label the objects as "1"and the background as " 0 " commonly.It was started around 1970's but because of following reasons there is still no robust solution towards it:

First reason is that there is too large content variety of images and second reason is that to judge the performance there is no benchmark standard. Segmentation is subjective because it may vary from human to human as per their requirements and its computation is costly.

Segmentation algorithms are of two types based on:

1) Grey level similarity and

2) Grey level discontinuity.

Both algorithms are categorized into three categories.

Algorithm based on 'grey level discontinuity' has following categories:

1. Detection of isolated points

2. Detection of lines

3. Detection of edges

There are three categories of algorithm based on 'grey level discontinuity':

1. Thresholding technique

2. Region growing

3. Region splitting and merging

Image segmentation is one of themost important steps leading to the analysis of processed image data.

Fig 1 shows the procedure for image analysis.

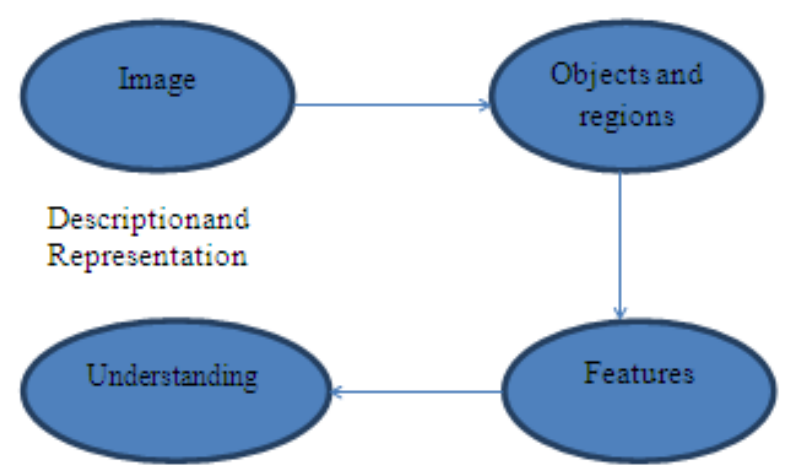

Fig 1: Procedure for image analysis 
There are three steps to extract the information from an image:

Step 1: Segment the image into objects or regions

Step 2: Describe and represent these segmented regions in a form which is suitable for computer processing

Step 3: Recognize and interpret the features of an image

This paper is organized as follows: Section II provides us the information about various image segmentation techniques. Section III is focused on comparison between different approaches to image segmentation, Section IV presents various applications ofimage segmentation and Section V presents the conclusion.

\section{Segmentation Techniques}

There are various segmentation techniquesbased on grey level discontinuity and grey level similarity. First we will discuss the various techniques based on grey level discontinuity.

\subsection{Grey Level discontinuities:}

2.1.1. Detection of Point [2]: Isolated points in an image are those which have abruptly different grey level values than those of its surrounding points. The most common approach to measure the discontinuities is to use a square mask. Mask is moved over the image, at each image point computing the sum of coefficients with the corresponding gray values. If we consider the mask $3 * 3$, response of the mask at any point in the image is:

$$
\mathrm{R}=\mathrm{W}_{1} \mathrm{Z}_{1}+\mathrm{W}_{2} \mathrm{Z}_{2}+\mathrm{W}_{3} \mathrm{Z}_{3}+\ldots \ldots+\mathrm{W}_{9} \mathrm{Z}_{9}
$$

$$
g(x, y)=\left\{\begin{array}{c}
1 \text { if }|\mathbf{R}(\mathbf{x}, \mathbf{y})| \geq T \\
\text { 0otherwise }
\end{array}\right.
$$

2.1.2 Detection of lines [2]: The various masks are used for detecting horizontal line, vertical line, line at $+45^{\circ}$, line at $-45^{\circ}$ (slanting lines). The response is maximum when the masks will pass through the corresponding lines. Various masks can be used for this purpose.

2.1.3 Detection of Edges [2] [13]: An edge is a boundary between two regions with relatively distinct grey level properties.

Various operators are used for edge detection:

a) Gradient operator: In gradient First order derivative is used and magnitude of First order derivative is used to detect the presence of edges an image.

$\nabla f \equiv \operatorname{grad}(f) \equiv\left[\begin{array}{l}g_{x} \\ g_{y}\end{array}\right]=\left[\begin{array}{l}\frac{\partial f}{\partial x} \\ \frac{\partial f}{\partial y}\end{array}\right]$

Magnitude of the gradient vector is:

$$
\operatorname{mag}(\nabla f)=\sqrt{g_{x}+g_{y}}
$$

Direction of gradient vector is:

$$
\alpha(x, y)=\tan ^{-1}\left[\frac{g y}{g_{x}}\right]
$$

Gradient is given by Sobel operators, Prewitts operators, Roberts, cross gradient operators.

b) Laplacian operator: In laplacian Second order derivative is used for edge detection in an image.

Magnitude of Second order derivative is used to detect whether the edge lies on dark side or light side of an edge.

Laplacian of 2D function $f(x, y)$ is a second order derivative defined as:

$\nabla^{2} \mathrm{f}=\mathbf{\partial}^{2} \mathrm{f} / \mathbf{\partial} \mathrm{x}^{2}+\mathbf{\partial}^{2} \mathrm{f} / \mathbf{\partial} \mathrm{y}^{2}$

Issues with Laplacian method are given as:

1) Unacceptably sensitive to noise

2) Magnitude of Laplacian results in double edges

3) Does not provide gradient, so can't detect edge direction 


\subsection{Based on Grey Level similarity:}

2.2.1. Region Oriented Segmentation [2]: This segmentation technique finds the region of interest directly instead of the boundaries dividing the regions.. This technique [3] uses neighborhood pixel properties.

Basic rules for segmentation:

Using segmentation algorithm $\mathrm{R}$ is divided into $\mathrm{n}$ sub regions $\mathrm{R} 1, \mathrm{R}_{2}, \mathrm{R}_{3}$

$\mathrm{R}_{\mathrm{n}}$ such that

1) $\quad \bigcup_{\mathrm{i}=1}^{\mathrm{n}} \mathrm{Ri}=\mathrm{Rindicates}$ that segmentation algorithm is complete in all respects

2) Riisconnected region for $i=1,2,3 \ldots \ldots \ldots n$ indicates points in region $R_{i}$ must be connected.

3) $\quad \mathrm{Ri} \cap \mathrm{Rj}=\varnothing$ indicates that region must be disjoint

4) $\quad \mathrm{P}(\mathrm{Ri})=\mathrm{T}$ indicates that $\mathrm{Ri}$ have same intensity

5) $\quad \mathrm{P}(\mathrm{Ri} \cup \mathrm{Rj})=$ False for any adjacent region $\mathrm{Ri}$ and $\mathrm{RJ}$

1) Region growing[2][12]: Grouping the pixels or sub regions into larger regions using pixel aggregation.

Take seed points as starting points, region grow by appending pixels to each seed point those neighboring pixels having similar properties.

The predicate $\mathrm{P}$ (property) to be used to include a pixel in either region is that the absolute difference between the gray level of that pixel and the grey level of the seed be less than the threshold value $\mathrm{T}$.

a)Choosetheright"seed"points;

b) Selectasetofsimilarity criteria;

c)Setupastoppingrule

Problems in region growing technique are given below:

1) Selection of the seeds points

2) Criteria of similarity

- Gray level's similarity / connectivity / texture / moments

3) Formulation of a stopping rule

- Growing a region should stop when no more pixels satisfy the criteria for inclusion in that region

Fig 2 represents the grouping of sub regions into larger regions i.e. region growing
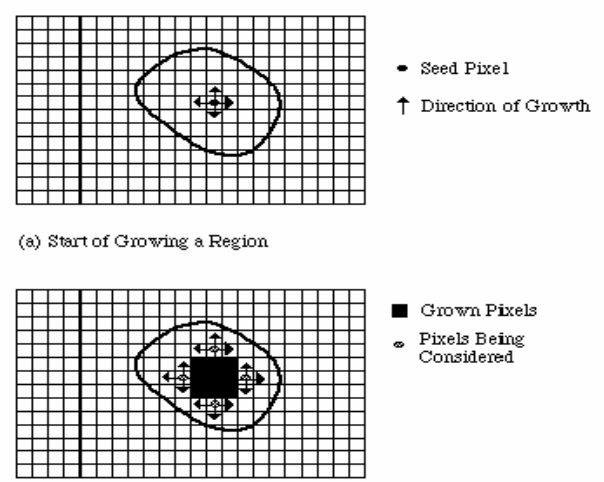

(b) Growing Process After a Few Iterations

Fig 2: Region Growing

2) Region splitting and merging[2] [11]:An image is initially divided into set of arbitrary sub images of disjoint regions and then merges and/or split operation is carries out based on certain criteria.

Let $\mathrm{R}$ represent the entire region and predicate $\mathrm{P}(\mathrm{Ri})$ is used to check the conditions. For any region Ri for $\mathrm{i}=$ 1 to $4, \mathrm{P}(\mathrm{Ri})=\mathrm{T}$ is applied and if it is false then subdivide the region into smaller and smaller quadrants. It is represented by quad tree.

Procedure:

a) Split the given region $\mathrm{Ri}$ into four disjointed quadrants when $\mathrm{P}(\mathrm{Ri})=$ false

b) Merge any adjacent regions RjandRk forwhich $\mathrm{P}(\mathrm{Rj} \cup \mathrm{Rk})=$ true

c) Stop when no further merging or splitting is possible. 
Fig 3 [2] represents split and merge technique by making quad tree.
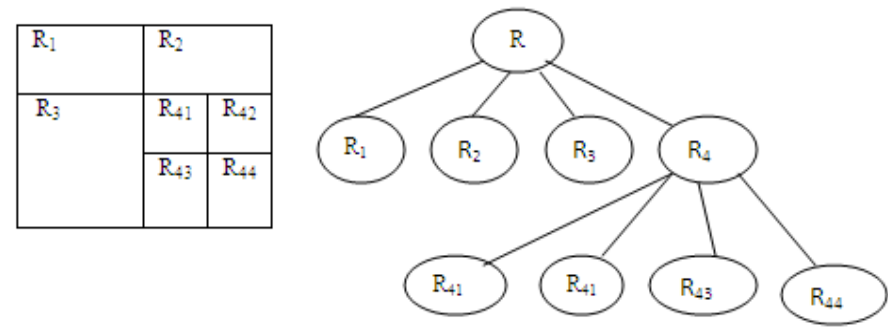

Figure 3: Quad tree

2.2.2 Clustering:Clustering (data grouping) is an initial procedure in image processing. It is an unsupervised learning task (use no training stages rather train themselves using available data). Clustering is mainly used when we know the classes are in advance. Pixels having similar properties are grouped into same cluster andsimilarity criteria are defined between pixels. The pixels are grouped into clusters and it is based on the principle that there is maximum intra class similarity and minimum the inter class similarity.

This technique has following types:

1) The K-means algorithm is an iterative technique that is used to partition an image into $K$ clusters. The basic algorithm is:

a)In this firstly centroids are assumed and according to that clustering is done.

b) Recompute the centroid by taking the mean of each cluster.

c) After recomputing the centroids, new clusters are obtained

d) This procedure continues until centroids are not changed and at last we obtain the final clusters

Fig $4[5]$ shows how to make clusters.

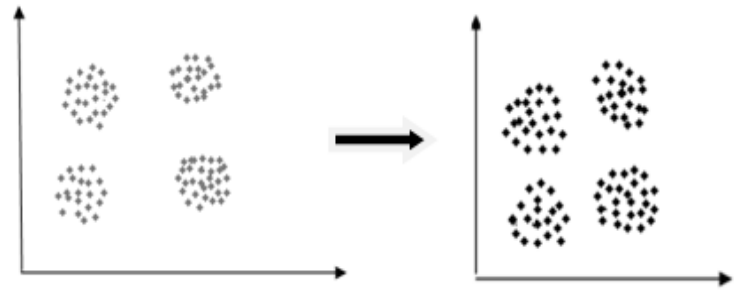

Figure 4: Clustering

Advantage of k-mean clustering: k-mean clustering is easy to implement

Hierarchical clustering is another type of clustering method which is explained below:

2) Hierarchical clustering [10]:We have given a set of $\mathrm{N}$ items to be clustered, and an $\mathrm{N} * \mathrm{~N}$ distance (or similarity) matrix, the basic process of Johnson's (1967) hierarchical clustering is this:

1. In first step assigning each item to a cluster, so that if we have $\mathrm{N}$ items, we now have $\mathrm{N}$ clusters, each cluster containing just one item. Suppose the distances (similarities) between the clusters the same as the distances (similarities) between the items they contain.

2. Find the closest or most similar pair of clusters and merge them into a single cluster, so that now we have one cluster less.

3. In third step, compute distances (similarities) between the new cluster and each of the old clusters.

4. Repeat steps 2 and 3 until all items are clustered into a single cluster of size $\mathrm{N}$.

3) Fuzzy basedclustering segmentation[4][5][10]:

Inimagesegmentation,analysis, andotherlevelsofimageprocessing,uncertainty isa main factorthat leadstounfavorableresultsforfixedalgorithms. Going further,theresultofprecedingprocessingwillinfluencethe performanceofsubsequentprocessing, whichasksforcertain degreeofflexibility(fuzzycharacteristic)inimageprocessing algorithms.FuzzySet Theorycan beusedin 
clusteringandit allows fuzzy boundaries clustering.Themaindrawbackofthisalgorithmisthatitis difficulttoconfirm theattributeoffuzzymembersanditis complicatedforcalculatingin thisalgorithm.

Fuzzy membership function can be used to represent the degree of some properties and fuzzy IF-THEN rules can be used to perform approximate inference

2.2.3.Thresholding[12]:Itisimportant for segmentation. This is the simplest segmentation technique based on the values of pixels. It is an operation in which a reference grey level is selected using histogram such that that the object and background can be separated.

Fig 5 [10] shows thresholding using histogram.

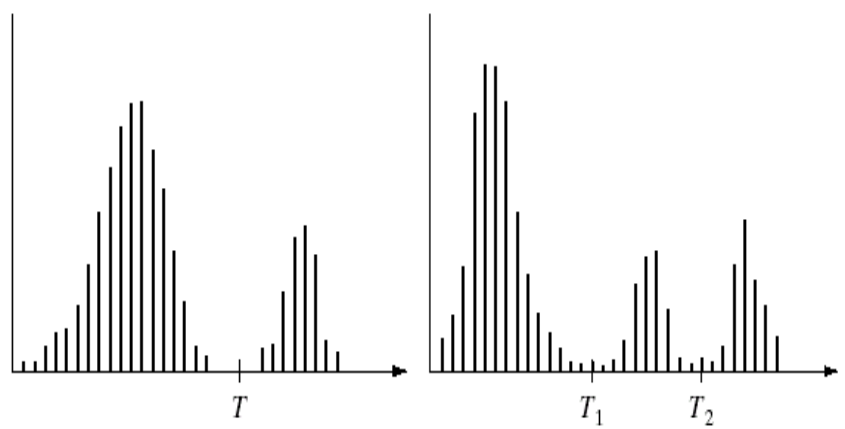

Figure 5: Thresholding using histogram[10]

There are more than one threshold values in multilevel thresholding and having multiple light objects on dark background. Using this technique,

multilevel images are converted into binary images by choosing proper threshold value $\mathrm{T}$ which is used to divide an image pixel into different regions and is used to separate the objects from background.

With threshold value, gray values of an image are compared and foreground \& background portions are separated.

1 ;if $\mathrm{f}(\mathrm{x}, \mathrm{y})>\mathrm{T}$ (object) \&

$0 ;$ if $(\mathrm{x}, \mathrm{y})<=\mathrm{T}$ (background)

1)Ostu's Method [9 [11]]: It automatically performs clustering based thresholding (global).It converts gray level image to black and white. Ostu, try to minimize the intra class variance or maximize the inter class variance.

$\sigma_{\text {between }}^{2}(T)=W_{b} W_{f}\left(\mu_{b}-\mu_{f}\right)$

$\sigma_{\text {within }}^{2}=W_{b} \sigma^{2}+W_{f} \sigma^{2}$

Where $\sigma^{2}$ denotes variance

$\mathrm{W}$ and $\mu$ are the weight and mean of pixels of background and object respectively. It is easier to find out the variance between the classes.

Fig 6 [9] shows the histogram of given image
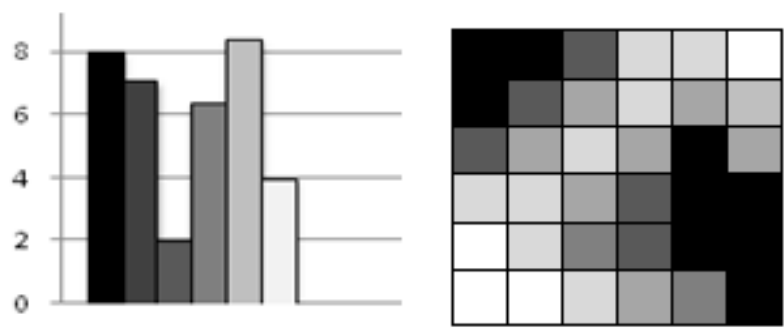

Figure 6: Histogram of an image[9] 


\section{Background}

Fig 7 [9] represents the values of background pixels
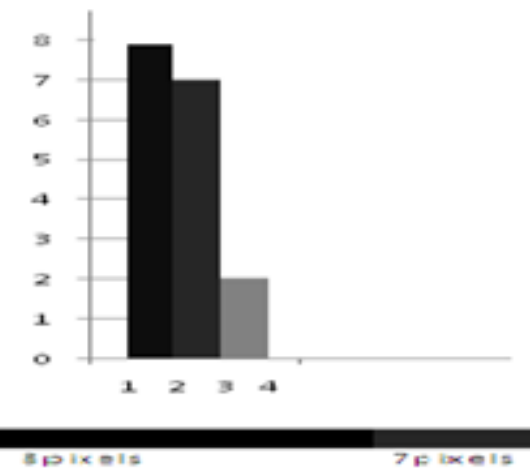

Fig 7: Background pixel

Here, Threshold is taken as 3

Weight $\mathrm{W}_{\mathrm{b}}=\frac{8+7+2}{36}=0.4722$

Mean $\mu_{\mathrm{b}}=\frac{(0 \times 8)+(1 \times 7)+(2 \times 2)}{17}=0.6471$

Variance $\sigma_{b}{ }^{2}=\frac{\left((0-0.6471)^{2} \times 8\right)+\left((1-0.6471)^{2} \times 7\right)+\left((2-0.6471)^{2} \times 2\right)}{17}$

$=0.4637$

\section{FOREGROUND}

Fig 8 [9] represents the values of foreground pixels

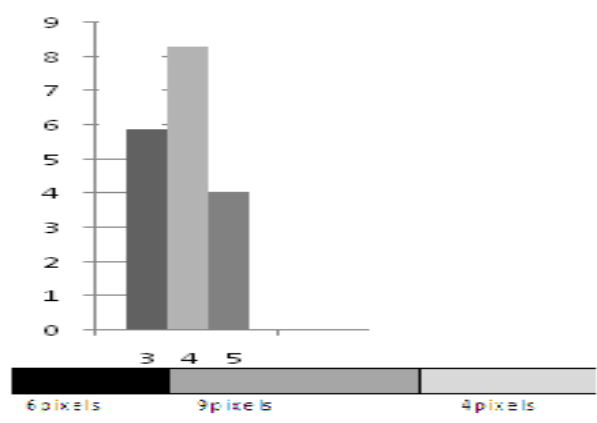

Fig 8: Foreground Pixels

Weight $\mathrm{W}_{\mathrm{f}}=\frac{8+9+4}{36}=0.5278$

Mean $\mu_{\mathrm{f}}=\frac{(3 \times 6)+(4 \times 9)+(5 \times 4)}{19}=3.8947$

Variance $\sigma_{\mathrm{f}}^{2}=\frac{\left((3-3.8947)^{2} \times 6\right)+\left((4-3.8947)^{2} \times 9\right)+\left((5-3.8947)^{2} \times 4\right)}{17}$

$$
=0.5152
$$

Within Class Variance $\sigma_{\mathrm{w}}{ }^{2}=\mathrm{W}_{\mathrm{b}} \sigma_{\mathrm{b}}{ }^{2}+\mathrm{W}_{\mathrm{f}} \sigma_{\mathrm{f}}^{2}$
$=0.4772 * 0.4637+0.5278 * 0.515$
$=0.4909$

Table 1 [9] shows the values of threshold values of "within class variance" and "between class variance" at $\mathrm{T}=3$

Table 1: Threshold values

\begin{tabular}{|l|l|l|l|l|l|l|}
\hline Threshold & $\mathrm{T}=0$ & $\mathrm{~T}=1$ & $\mathrm{~T}=2$ & $\mathrm{~T}=3$ & $\mathrm{~T}=4$ & $\mathrm{~T}=5$ \\
\hline Within & $\sigma^{2}{ }_{\mathrm{w}}=$ & $\sigma^{2}{ }_{\mathrm{w}}=$ & $\sigma^{2}{ }_{\mathrm{W}}=$ & $\sigma^{2}{ }_{\mathrm{w}}=$ & $\sigma^{2}{ }_{\mathrm{w}}=$ & $\sigma^{2}{ }_{\mathrm{w}}=$ \\
class & 3.119 & 1.526 & 0.55 & 0.49 & 0.977 & 2.249 \\
variance & 6 & 8 & 61 & 09 & 9 & 1 \\
\hline Between & $\sigma^{2}{ }_{\mathrm{B}}=0$ & $\sigma^{2}{ }_{\mathrm{B}}=$ & $\sigma^{2}{ }_{\mathrm{B}}=$ & $\sigma^{2}{ }_{\mathrm{B}}=$ & $\sigma^{2}{ }_{\mathrm{B}}=$ & $\sigma^{2}{ }_{\mathrm{B}}=$ \\
class & & 1.592 & 2.56 & 2.62 & 2.141 & 0.870 \\
variance & & 8 & 35 & 87 & 7 & 5 \\
\hline
\end{tabular}


2) Iterative Thresholding [9]:In this method an initial value of threshold is assumed. The way for selecting a threshold value $\mathrm{T}$ follows these steps according to this algorithm:

1. An assumed $T$ is the average of minimum and maximum intensity value (not fixed, any value can be chosen as initial T).

2. An image is partitioned into two pixels regions using value of $\mathrm{T}$, $\mathrm{T} 1$ (all pixel values $<\mathrm{T}$ ) andT2 ( all pixel values $>$ T).

3. Calculate the average intensity values $\mathrm{n} 1$ and $\mathrm{n} 2$ of regions $\mathrm{T} 1$ and $\mathrm{T} 2$ respectively.

4. Compute a new value of $\mathrm{T}$ as

$\mathrm{T}=(\mathrm{n} 1+\mathrm{n} 2) / 2$

5. Repeat steps from 2 to 4 until difference between two successive values of $\mathrm{T}$ is minimal.

Application:Best suited for bimodal images

Advantage:This method is best suited for an image which has two data peaks (bimodal image). Its success is dependent on how well the histogram of an image can be partitioned.

Disadvantage: Its performance decreases for images having various illuminations.

2.2.4. Neural-networks based segmentation [10][12]:

An artificial neural network isuse to solve the medical image segmentation. It is totallydifferent fromother conventionalsegmentation algorithms.

Inthis algorithm, animageisfirstlymappedintoaneuralnetwork whereeveryneuron standsforapixel. Then,weextractimageedgesbyusingdynamicequationstodirectthestate ofevery neurontowards minimumenergydefined by neural network.

A neural net is an artificial representation of human brain that tries to simulate its learning process. An artificial neural network is often called a neural network or simply neural net.

Neuralnetworkbasedsegmentation havethreebasic characteristics [12]:

1)It is suitableforreal-time application because of its high parallel ability and fast computing capability

2)This algorithm is abletoestablishmodelingforanyprocess because it has high interaction amongprocessing units

3) It isinsensitivetonoise because of satisfactory robustness.

Advantages:

1. There is no need to write complicated programs.

2. It can fully utilize the parallel nature of neural networks

Disadvantage:

1) Overtraining should be avoided and;

2) Training time is long

III. Comparative analysis of various image segmentation techniques 


\begin{tabular}{|c|c|c|c|}
\hline $\begin{array}{l}\text { Segmentatio } \\
\text { n } \\
\text { Iechniques }\end{array}$ & $\begin{array}{l}\text { Mrethod } \\
\text { Descriptio } \\
\text { n }\end{array}$ & $\begin{array}{l}\text { Advantag } \\
\text { es }\end{array}$ & $\begin{array}{l}\text { Disadvantag } \\
\text {-es }\end{array}$ \\
\hline $\begin{array}{l}\text { 1. Edge } \\
\text { detecrion } \\
\text { technique } \\
{[2][10] \text { [13] }}\end{array}$ & $\begin{array}{l}\text { It is based } \\
\text { on the } \\
\text { detection of } \\
\text { discontinuit } \\
\text { y and it } \\
\text { tries to } \\
\text { locate } \\
\text { points with } \\
\text { more or } \\
\text { les abrupt } \\
\text { changes in } \\
\text { gray level }\end{array}$ & $\begin{array}{l}\text { It works } \\
\text { well for } \\
\text { thoee } \\
\text { which } \\
\text { imagees } \\
\text { having } \\
\text { good } \\
\text { contrast } \\
\text { between } \\
\text { regions }\end{array}$ & $\begin{array}{l}\text { 1. Less } \\
\text { immune to } \\
\text { noise than } \\
\text { other } \\
\text { techniques } \\
\text { 2. It doesn't } \\
\text { work well if } \\
\text { there are } \\
\text { large no. of } \\
\text { edges amd } \\
\text { edges are ill } \\
\text { defined }\end{array}$ \\
\hline $\begin{array}{l}\text { 2.Region } \\
\text { based } \\
\text { technique } \\
{[2][10] \text { [12] }}\end{array}$ & $\begin{array}{l}\text { In this, } \\
\text { Crouping } \\
\text { of pixels } \\
\text { into } \\
\text { homogeneo } \\
\text { us regions. } \\
\text { Andit } \\
\text { includes } \\
\text { region } \\
\text { growing, } \\
\text { region } \\
\text { splitting, } \\
\text { region } \\
\text { merging or } \\
\text { their } \\
\text { combinatio } \\
\text { n. }\end{array}$ & $\begin{array}{l}\text { 1. Mlore } \\
\text { noise } \\
\text { immune } \\
\text { than edge } \\
\text { detection } \\
\text { approach. } \\
\text { 2. It works } \\
\text { well when } \\
\text { region } \\
\text { homogenei } \\
\text { ty criterion } \\
\text { is easy to } \\
\text { define. }\end{array}$ & $\begin{array}{l}\text { 1. It is quite } \\
\text { expensive } \\
\text { both in } \\
\text { computation } \\
\text { al time and } \\
\text { memory } \\
\text { 2. Selection } \\
\text { of eeed } \\
\text { points and } \\
\text { the order in } \\
\text { which } \\
\text { regions are } \\
\text { to examines } \\
\text { is diffoult }\end{array}$ \\
\hline $\begin{array}{l}\text { 3. Thresh- } \\
\text { olding }[2]\left[\begin{array}{ll}10 \\
{[12]}\end{array}\right.\end{array}$ & $\begin{array}{l}\text { It requires } \\
\text { that the } \\
\text { histogram } \\
\text { of an image } \\
\text { has a no. of } \\
\text { peaks and } \\
\text { each peak } \\
\text { corresponds } \\
\text { to a region }\end{array}$ & $\begin{array}{l}\text { 1. It does } \\
\text { not require } \\
\text { a prior } \\
\text { inforpatio } \\
\text {-n of the } \\
\text { image } \\
\text { 2.It has } \\
\text { less } \\
\text { computatio } \\
\text { nal } \\
\text { complexity }\end{array}$ & $\begin{array}{l}\text { 1. It does not } \\
\text { work well } \\
\text { for an image } \\
\text { without any } \\
\text { obvious } \\
\text { peaks or with } \\
\text { broad and } \\
\text { flat valleys; }\end{array}$ \\
\hline $\begin{array}{l}\text { 3.1. Ostu's } \\
\text { method [9] }\end{array}$ & $\begin{array}{l}\text { Automatically } \\
\text { perfoms } \\
\text { clustering } \\
\text { based } \\
\text { thresholding } \\
\text { (global). }\end{array}$ & $\begin{array}{l}\text { 1. It is a } \\
\text { simplest } \\
\text { approach } \\
\text { 2. automaticay } \\
\text { perfoms } \\
\text { clustering } \\
\text { based } \\
\text { threaholding }\end{array}$ & $\begin{array}{l}\text { It is time } \\
\text { consuming }\end{array}$ \\
\hline $\begin{array}{l}3.2 \text {. } \\
\text { Iterative } \\
\text { Thresholdin } \\
\mathrm{g}\end{array}$ & $\begin{array}{l}\text { An initial } \\
\text { value of } \\
\text { threshold is } \\
\text { assumed. }\end{array}$ & $\begin{array}{l}\text { Best suited for } \\
\text { bimodal } \\
\text { images }\end{array}$ & $\begin{array}{l}\text { Its performance } \\
\text { decreases for } \\
\text { images having } \\
\text { various } \\
\text { illuminations. }\end{array}$ \\
\hline $\begin{array}{l}\text { S.Neural } \\
\text { Network } \\
\text { technique } \\
{[10][12]}\end{array}$ & $\begin{array}{l}\text { It uses neural } \\
\text { networks to } \\
\text { perform } \\
\text { classification } \\
\text { or data } \\
\text { clustering }\end{array}$ & $\begin{array}{l}\text { 1. There is no } \\
\text { need to urite } \\
\text { complicated } \\
\text { programs. } \\
\text { 2. It can fully } \\
\text { utilize the } \\
\text { parallel nature } \\
\text { of neural } \\
\text { networks }\end{array}$ & $\begin{array}{l}\text { Overtraining } \\
\text { should be } \\
\text { avoided and } \\
\text { Training time is } \\
\text { long }\end{array}$ \\
\hline $\begin{array}{l}\text { 6. Clus treing } \\
{[10]}\end{array}$ & $\begin{array}{l}\text { Grouping of } \\
\text { pixels is done } \\
\text { based on } \\
\text { similarity } \\
\text { criteria }\end{array}$ & $\begin{array}{l}\text { 1. k-mean } \\
\text { clustering is } \\
\text { easy to } \\
\text { implement } \\
\text { Its time } \\
\text { complexity is } \\
Q(n) \text {, where } n \\
\text { is the number } \\
\text { of pattems. }\end{array}$ & $\begin{array}{l}\text { 1. Result is } \\
\text { sensitive to the } \\
\text { selection of the } \\
\text { initial random } \\
\text { centroids } \\
2 \text {. WVe cannot } \\
\text { show the } \\
\text { clustering details } \\
\text { as hierarchical } \\
\text { clustering does. }\end{array}$ \\
\hline $\begin{array}{l}\text { 6.1.Fuzzy } \\
\text { technique } \\
{[4][5][10]}\end{array}$ & $\begin{array}{l}\text { It uses fuzyy } \\
\text { operators, } \\
\text { properties, } \\
\text { mathermatics, } \\
\text { and inference } \\
\text { rules, and } \\
\text { provides a } \\
\text { method to } \\
\text { handle the } \\
\text { uncertainty } \\
\text { inherent in } \\
\text { variety of } \\
\text { problems }\end{array}$ & $\begin{array}{l}\text { 1.Mermbershi-p } \\
\text { function can be } \\
\text { used to } \\
\text { represent the } \\
\text { degree of some } \\
\text { properties, } \\
\text { fuzay IF- } \\
\text { THED rules } \\
\text { can be used to } \\
\text { perform } \\
\text { approximate } \\
\text { inference } \\
\text { 2.It is fast }\end{array}$ & $\begin{array}{l}\text { 1. Determination } \\
\text { of fuzey } \\
\text { membership } \\
\text { function is not a } \\
\text { trivial job } \\
\text { 2.Performance is } \\
\text { limited }\end{array}$ \\
\hline
\end{tabular}




\section{Applications}

Some of the practical applications of image segmentation are:

Image segmentation is used in medical applications, segmentation techniques are used to locate tumors and other pathologies, to measure tissue volumes, diagnosis and study of anatomical structure etc.

Image segmentation techniques are used for pedestrian detection, face detection, brake light detection, to locate objects in satellite images (roads, forests, crops, etc.)

These techniques are used for various recognition taskslike face recognition, fingerprint recognition etc. Segmentation is also used in traffic control systems, content-based image retrieval, in machine vision etc.

\section{Conclusion}

Image segmentation plays a key role for image analysis and for processing of an images and hence it becomes a prime concern to select appropriate method which incorporates all parameters such as cost, computational complexity and application area etc. to provide accurate segmentation.

In this paper, the overview of various image segmentation techniques and their comparison is given. These techniques are very important for pattern recognition using edges, images and points. These techniques are used in many advanced machines for identification of faces, images etc. Image segmentation is also used in medical science to detect cancerous cells from medical images and other application areas.

\section{References}

[1]. C. Pantofaru, M. Hebert, A comparison of image segmentation algorithms, Tech. Rep. CMU-RI-TR-05-40, CMU (2005).2, 14.

[2]. Digital Image Processing, Rafael C. Gonzalez \& Richard E. Woods, Second Edition 2002, Prentice Hall.

[3]. W. K. Pratt, "Image Segmentation,” in Digital image processing, 4nd ed. Wiley, 2008, pp. 579-622.

[4]. V. K. Dehariya, S. K. Shrivastava, R. C. Jain, "Clustering of Image Data Set Using K-Means and Fuzzy K-Means Algorithms", International conference on CICN, pp. 386-391, 2010.

[5]. V. K. Dehariya, S. K. Shrivastava, R. C. Jain, “Clustering of Image Data Set Using K-Means and Fuzzy K-Means Algorithms”, International conference on CICN, pp. 386- 391, 2010.

[6]. F .Z. Kettaf, D. BI, J. P., “A Comparison Study of Image Segmentation by Clustering Technique”, Proceedings of ICSP, pp. 1280$1282,1996$.

[7]. IvanaDespotović, "Spatially Coherent Fuzzy Clustering for Accurate and Noise-Robust Image Segmentation", IEEE Signal Processing Letters, Vol. 20, No. 4, April 2013

[8]. Satish Kumar, RaghavendraSrinivas, "A Study on Image Segmentation and its Methods"

[9]. SheenamBansal, Raman Maini, “ A Comparative Analysis of Iterative and Ostu'sThresholding Techniques”

[10]. H.P. Narkhede, "Review of Image Segmentation Techniques"

[11]. SheenamBansal, Raman Maini, "Performance Analysis of Color Based Region Split and Merge and Otsu's Thresholding Techniques for Brain Tumor Extraction"

[12]. Jay Acharya, SohilGadhiya, KapilRaviya,"SEGMENTATION TECHNIQUES FOR IMAGEANALYSIS: A REVIEW"

[13]. N. Senthilkumaran and R. Rajesh, "Edge Detection Techniques for ImageSegmentation - A Survey of Soft Computing Approaches" 